Witold Lenart, Małgorzata Roge

\title{
THE IMPACT ASSESSMENT OF CONSTRUCTION AND OPERATION OF THE TRANSIT GAS PIPELINE RUSSIA - WESTERN EUROPE ON ENVIRONMENT
}

\section{THE INVESTMENT PROJECT}

The realisation of the transit gas pipeline Russia - Western Europe started in 1993. Construction of the first line lasted four years and ended in the Fall of 1999. The length of the Polish section of this line is about $680 \mathrm{~km}$. Its route was conditioned by the locations of connections on the boundaries of Poland with Belarus' and Germany, the assumed minimum distance from the densely populated areas, and the stimulation of determination of the possibly short route of the pipeline. It was attempted to stake the pipeline across the agricultural areas. Resulting from the efforts made in order to comply with such requirements the pipeline crosses the area of Poland from the East to the West along a line close to the straight one. The construction of the pipeline started at the western border, with the first section of more than $100 \mathrm{~km}$ treated as a good testbed. The route of the pipeline across Poland is shown in Fig 1.

The pipeline, built of steel pipes of the diameter of $1400 \mathrm{~mm}$ and standard thickness of the walls $-19.2 \mathrm{~mm}$ - transports gas under the maximum working pressure of $8.4 \mathrm{MPa}$. Five compressor stations, located in the area of Poland, ensure this level of gas pressure. For purposes of monitoring and enhancement of system's security the pipeline is sectioned by the linear valve stations every $20-35 \mathrm{~km}$.

During the construction of the pipeline two basic working regimes were used: open trenching and the technique without open excavation. No overland stretches were envisaged. In the framework of the technique without open excavation three methods were adopted: directional drilling, micro tunnelling and stream working. The basic method of proceeding in the particular case here considered was the open trenching. In this case the procedure of installation of the pipeline was composed of the following steps: preparation of the construction support infrastructure, staking of the pipeline route in the field, clearing of the right-of-way from any kind of vegetation, removal of the topsoil (the vegetable mould), laying of pipes along the future trench, welding of the single pipes into longer sections of the pipeline, execution of 


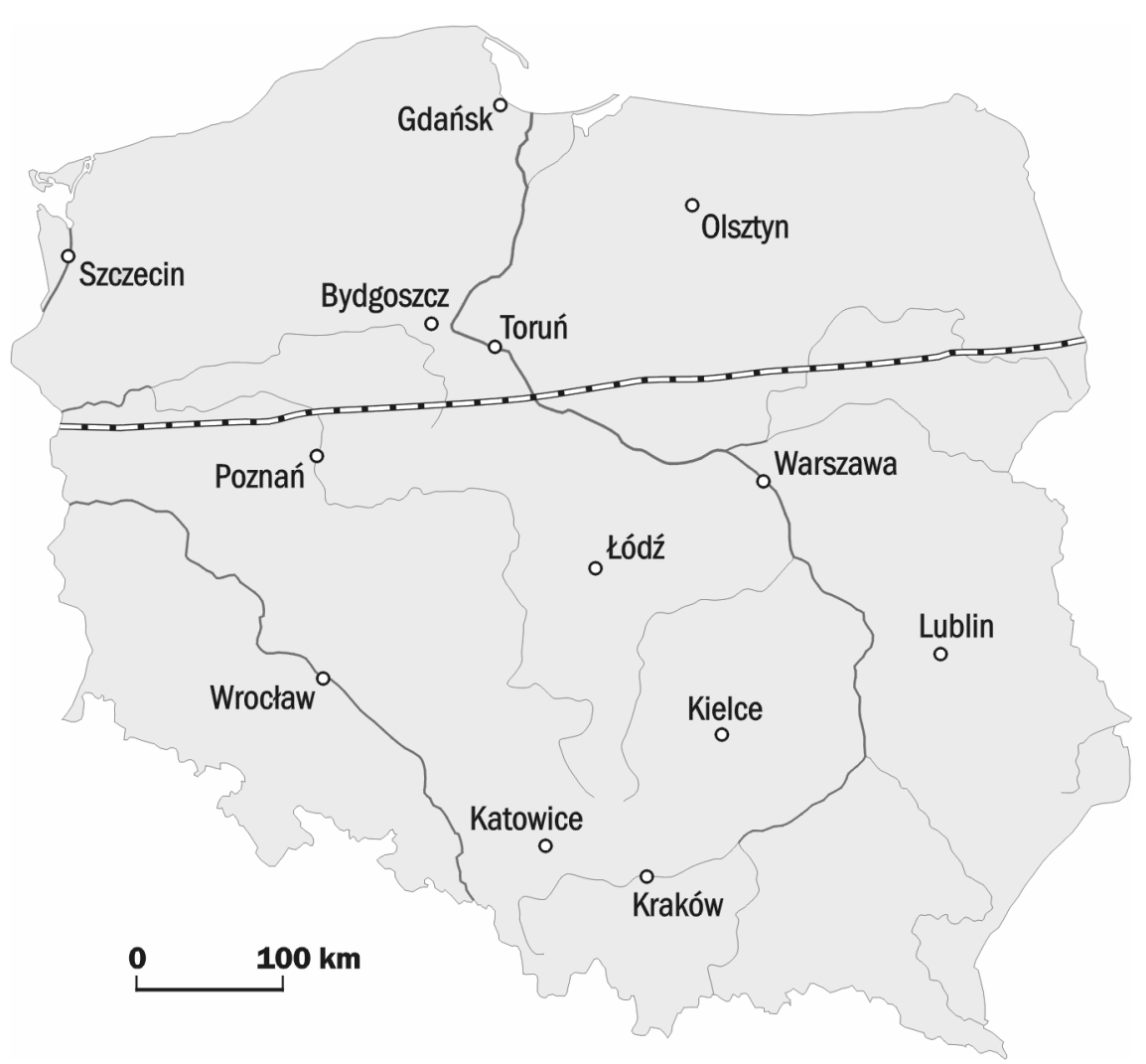

Fig. 1. The route of the transit gas pipeline across Poland.

the excavation, potentially also lowering of the groundwater table level by pumping out water, lovering of the welded sections of the pipeline into the trench, welding of the sections of the pipeline, backfilling of the trench, hydrostatic test of the long sections of the pipeline, restoration of the rightof-way. The methods, which do not involve excavation allow for avoiding a part of the negative impact on the environment. They are not accompanied by the clearing of the right-of-way of the vegetation, nor by the actual doing of the trenching. These methods require certain appropriate conditions. Thus, for instance, some of them are feasible only for compact soils. In addition, these methods are several times more expensive than the open trenching technique. All these circumstances caused that the systems without excavation were used only in cases of crossing of some of the roads and water flows, and much more rarely when passing through the areas valuable from the point of view of nature.

Further on, the essential impact processes and the effects of disturbance of the environment by the construction and exploitation of the gas pipeline are presented. 


\section{THE PHASE OF CONSTRUCTION — GENERAL REMARKS}

The construction of the gas pipeline constituted a linear intervention, and thus, individual biotopes were not subject to the negative influence in their totality, but only partially. The majority of animals had the possibility of escaping to the neighbouring areas. High rates of mortality applied to the small mobile species, that is - the Annelidae, the molluscs, the dragonfly larvae, as well as other water insects. Movements of machines, construction and transport equipment were accompanied by the emission of exhaust gases, dusts and noise. The limits of the ecological disturbances caused by noise during the installation work depended upon the sensitivity of individual species. An excessive noise could, in particular, cause that animals would avoid the biotopes in which they could potentially breed, were forced to leave the neighbourhood of the construction site in the search for food, and birds would abandon the eggs already laid or the nestlings. These damages could arise in cases when construction work was carried out during the breeding or nestling periods, or during the rest of the migratory birds in the forests, groves, bushy areas, and within the wet grasslands.

The heavy equipment used brought about in the neighbourhood of the construction site and the storage places the bruises on the tree trunks and the breaking of branches. The most important impact was associated with the indirect consequences of the conduct of construction work, that is - with the change in the structure of biotopes, especially in the forests and on the wetlands.

Soil was made denser over the areas and routes of storage and transport of equipment, making oxygen access difficult, and leading to disturbances in the functioning of soil organisms. In these areas soil temporarily interrupted fulfilment of most of its functions of a biotope for the micro- and macroorganisms. In some places, due to the leakage of fuels, lubricants, and oils from the construction machines, soil pollution would occur, not only toxic for the soil itself, but also threatening the quality of the groundwater.

The harmony and aesthetics of landscape were spoiled by the storage areas, the right-of-way, and the equipment gathered there, as well as the sites of an unorderly treatment of waste.

\section{THE PREPARATION OF THE CONSTRUCTION BASE}

The very first element of the project work in the field was the construction of the offices and premises for the employees, establishment of the surfaces necessary for the storage of construction materials (pipes, sand, cement weights for loading the pipeline on the wetlands, etc.), laying of the telecommunication network, as well as installation of the sanitary and transport facilities.

All these kinds of work were connected with the destruction of the vegetation cover in the areas taken for storage and transport use, followed by 
compacting of the soil, and the possibility of polluting it with the fuels and lubricants, originating from the construction machines, as well as emission of noise and the disruption of landscape by the objects erected.

\section{CLEARING OF THE RIGHT-OF-WAY}

After the route of the pipeline in the terrain had been staked, a segment of the right-of-way of the length of several hundred metres and the width of 32 metres (especially in the valuable areas and in the forests this width would be limited to $26 \mathrm{~m}$ ), was cleared of any vegetation whatsoever. Such way, devoid of any vegetation, constituted an obstacle to the spread of plants and small animals, entailing isolation of habitats. It thus made genetic exchange within a population difficult, if not impossible. Further, it would limit the possibility of finding refuge, food and breeding conditions for the smaller animals. The removal of vegetation exposed the soil to the direct operation of the sun, which resulted in its excess drying during the sunny days and to washing away during the abundant rains.

\section{REMOVAL OF THE TOPSOIL (VEGETABLE MOULD)}

The removal of the upper layer of the soil by the bulldozers caused the destruction of the natural levels and structures of the soil, as well as high mortality of the micro-organisms and the small mobile macro-organisms living in the soil.

The topsoil, stockpiled on one side of the right-of-way, underwent excess drying, entailing mineralisation of the organic compounds. In addition, a significant weight of the humus heap made the soil under it denser, and blocked the access of oxygen, which brought definite disturbances in the functioning of the soil organisms. This soil temporarily interrupted the fulfilment of the majority of its functions of a biotope for the micro- and macro-organisms. Yet, owing to the high stability and the significant self-regeneration capacity the renewal of the biocoenoses of the "soil ecosystem" should have proceeded relatively quickly.

\section{STRINGING OF PIPES ALONG THE FUTURE TRENCH, PIPE WELDING, TESTING OF SECTIONS}

Individual pipes were transported from the storage sites and strung along the future trench. Linking of the individual pipes to form long sections of the pipeline was done through welding. The places of joining were checked by X-raying and ultrasonography.

Soil got compacted under the weight of the pipes, which made the access of oxygen to it more difficult, and disturbed the infiltration of water, as well as functioning of plants and soil organisms. Welding and testing were accompanied by the emission of air pollution and the ultra sounds. These impacts, 
however, were not really significant. Much more important effects were brought about by the transport of pipes over the area, requiring the destruction of significant surfaces, especially in places, where manoeuvres were being done.

\section{TRENCHING}

The subsequent step was the ditching of the trench having the surfacelevel width of some $4-5$ metres and the depth of 2.5 to 5 metres. The actual depth of the trench resulted from the diameter of the pipes and the minimum safe cover of the pipeline, which amounted to 0.8 metre. During trenching the inorganic subsoil was stockpiled on the other side of the right-of-way with respect to the humus heap.

This stage of the construction work disturbed strongly the migration of the groundwater, since it was frequently associated with the cutting through of the shallow aquifer layers. Cutting through these layers might have caused disturbance to the supply of the aquifers, like resulting from the outflow of water from the shallower to the deeper layers, or the inflow of water to the trench. The trench itself might have become a local hydrogeochemical window, facilitating the penetration of pollutants into the water.

Besides, the deep trench with steep slopes, often filled with water, constituted a barrier to the migration of animals. Many of them fell into the trench and, as they could not get out of it, they drawned, became an easy prey or die of hunger.

The gas pipeline crossed the biggest Polish rivers: Odra, Warta, Vistula, and Narew, along with several middle sized rivers and a great many small rivers, creeks, and land improvement ditches. Most of these flows were crossed with the open trenching method. Application of this method requires construction of a dam across the water flow. Formation of the dam was associated with the increase of the rubble volume and a strong disturbance to the water outflow and runoff. It was also an obstacle to the animals migrating along the water flows. During the trenching the sediments would get elevated from the bottom, entailing the worsening of the physico-chemical parameters of water, mainly through the increase of concentration of the mineral suspended matter. The greatest hazard to the aquatic environment of these water flows was brought by the intensified transport of the organic sediments. They raised the oxygen demand to the degree disturbing the environmental conditions of the aquatic animal world. It would also sometimes happen that the inadequately selected diameter of the tube, carrying the water of the flow crossed, resulted in the flooding of the neighbouring areas.

\section{DRAINING OF THE TRENCH}

The installation work on the pipeline was being done in a dry trench. Hence, it was necessary to drain the trench in the areas with higher groundwater 
table levels. Two methods were mainly used for this purpose, that is - the loam filters and the horizontal draining tube dug in at the depth of $50 \mathrm{~cm}$ below the bottom of the trench. Lowering of the groundwater table level not only entailed the losses to the groundwater, but also resulted in the emergence of the depression cone. The radius of the depression cone, dependent upon the kind of soil and the duration of pumping, was of the order of a dozen metres. The depression thus arising was filled, conforming to the hydraulic slope, with the water originating from the neighbouring areas. The depression cone established therefore changed the direction of water outflow. Lowering of the groundwater table level within the reach of the cone entailed excess drying of the soil. An indirect effect of the decreased soil humidity was mineralisation of the organic compounds contained in it and the activation of the biogenes. The decreased availability of water for the plants strongly influenced their vegetation. After the lowering of the groundwater table level was discontinued, the previous state of things would be brought back over a couple of days or weeks, depending upon precipitation.

There were also significant impacts related to the release of the water, pumped away from the trench, to the watercourses and other water bodies. Such releases caused important changes in the water levels and in the physico-chemical parameters of water, meaning their pollution with mineral suspended matter. In places, where the releases were too abrupt and abundant there also occurred raising of the sediments from the bottom, deformation of the river channel, and, after the channel discharge capacity was exceeded, flooding of the neighbouring areas.

\section{LOWERING OF THE WELDED PIPELINE SECTIONS TO THE TRENCH, FURTHER WELDING INTO LONG STRETCHES AND BACKFILLING OF THE TRENCH}

After the segments of the pipeline were joined into long sections, backfilling of the trench started. Only the natural material of the subsoil was used for this purpose.

The directional outflow of groundwater may take place along the pipeline. The loosening of the soil facilitates the draining process. In order to limit the resulting negative impact the soil around the pipe was compacted during the filling of the trench.

An appropriate thickening of the material around the pipeline prevents, or at least mitigates, the draining phenomenon. This phenomenon consists in an intensified outflow of groundwater in places, where soil got loosened. Yet, vibrations of the pipeline under normal functioning may amplify the phenomenon again.

In the areas, where the groundwater table level is shallow, the largediameter pipeline might have formed a barrier across the shallow groundwater levels and changed, in particular, the direction of outflow of the intercover waters, or partly cut off the permeable layer. By forming an artificial 
water divide it could therefore bring a change in the conditions of water supply on some areas.

Where the areas crossed by the pipeline have a diversified relief, this relief might have got smoothed and evened out in some places. This was caused by the limited possibilities of bending the pipeline, forcing the shallower laying of the pipeline in the valleys and the ditching of deeper trenches on the mounds.

\section{THE HYDROSTATIC TEST OF THE PIPELINE}

During the hydrostatic test the sections of the pipeline were subject to the water pressure of approximately 140 bar, that is - 1.6 times the working pressure of the gas transported.

The impact related to the hydrostatic test was associated with the take up and release of the water necessary for the test, that is - approximately $10,000 \mathrm{cu}$. $\mathrm{m}$ of water per pipeline segment. Water was taken from the flows and surface reservoirs. In places devoid of the sufficient resources of surface waters, groundwater was used. In the case of flows with low intensity of discharge and the reservoirs of low capacity the take up of a large volume of water entailed big fluctuations in the water levels. An important decrease of the discharges in flows changed the environmental conditions of existence of the animal world in a disadvantageous manner.

During the hydrostatic test the water used for this purpose was polluted with the mineral material. In view of the nature of pollution the release of water after the hydrostatic test was associated with the analogous environmental hazard as in the case of release of water resulting from the draining of the trench.

\section{RESTORATION}

Restoration of the right-of-way encompassed three essential operations:

- loosening of the subsoil on the areas, where heavy equipment moved around, in order to reduce the potential compactness,

- spreading of the humus layer over the right-of-way,

- treatment of the humus layer in a way to allow the start of sowing and planting.

Owing to the land improvement work the right-of-way ought to have been brought back to the use it had before the project started. This was done successfully in the majority of the agricultural areas. A couple of years after the land improvement has been finished the route of the gas pipeline was supposed to be marked only by the yellow pipeline makers. Troubles were noted in all these places, where the respective landowner did not sufficiently care or where the staff allowed the humus to be taken away.

Compressor stations and other voluminous structures, as well as crossings through the forests constitute the persistent changes in the landscape. These 
changes result from the technological requirements. Leaving of the treeless belt of 8 metres of width above the pipeline results from the requirement of protecting it against destruction by the tree roots. Cutting of the forest ecosystem by such a forest clearing certainly has an influence on the ecosystem, through which the pipeline runs. The trees that grow along the edge of the glade are adapted to grow inside of a forest, and not at its edge. The consequence of the increased insolation and the exposure to the blasts of wind is the weakening and the dropping out of the trees. In addition, the clearing constitutes a new type of habitat. New plant associations develop in it, namely grasslands and meadows, not encountered among the dense forest areas. They enrich the biodiversity, especially in the case of pine monocultures. On the other hand, the pipeline glade is also a route, through which synantropic species penetrate into the forest, and it makes migrations of the bigger animals more difficult, facilitating the task of the poachers when these animals cross the clearing.

\section{EXPLOITATION AND MONITORING}

The impact of the pipeline on the natural environment is much smaller during its normal functioning than during its construction.

Thus, erosion processes take place on the slopes that have not been adequately protected by the fascine and plantings. The furrows and pots caused by erosion reach in some cases quite important dimensions. The soil may also settle above the pipeline. This settling, though, is not very significant and occurs rather rarely. The strongest changes occurred in places, where the mineral material got insufficiently compacted during the backfilling of the trench.

The pipeline vibrates during the normal operation owing to the transport of high-pressure gas. These small movements may entail loosening of the soil in the vicinity of the pipe, leading to intensification of water draining.

A persistent, though slightly significant influence is constituted by the increased temperature of the soil above the pipeline. The botanical consequences of this effect will presumably be visible.

The routine inspections along the pipeline disturb the life of animals in the vicinity of the exploitation route. Frightening off the animals should, however, not be too oppressive in view of the low frequency of such drives.

Gas transport is accompanied by the emission of some quantities of it at the compressor stations. This is a more detailed technical question. Emission of methane from the pipeline along its route is practically null.

\section{SUMMING UP}

The impact of the construction of the gas pipeline on the natural environment is certainly much bigger than during its normal exploitation. The linear 
character of the investment project and the technical conditions of its realisation cause that many of the environmental changes are unavoidable. There is a permanent change introduced into the landscape, consisting in the cutting through of the forest ecosystems and the associated deforestation of the right-of-way of the gas pipeline. The majority of changes, though, are limited and local. It can be assumed that a temporary change is constituted by the synantropisation of the forest stands close to the right-of-way, the weakening of the viability of trees in the border zone of the forest, due to the change in the habitat conditions, or the disappearance of the aquatic and coastal vegetation.

The strongest impact is concentrated in the narrow belt of a couple of dozen metres of width, stretching along the pipeline. This strip was subject to detailed physiographic analysis, which demonstrated that the changes in the environment, mentioned here, took place first of all in these sections of the pipeline, which crossed the hydrogenic soils, and where water flows were crossed with the technique of the open trenching.

It was also essential that the methodological approach taken differed from the usual manners of analysing the environmental impact of an investment project. Detailed studies and observations were carried out according to all the separate phases of the construction process and normal functioning, rather than according to the impacts on the particular components of the environment. The approach required a deeper knowledge of the technique and technology of the work carried out. It turns out that such an approach makes it possible to draw a more complete list of impacts and to indicate in a more unambiguous way the causes - sources of hazard and changes. Owing to this, several recommendations could also be formulated aiming at mitigation of the negative impact upon the environment.

\section{REFERENCES}

Lenart W., Roge M., 2001, Yamal - Europe gas pipeline - a challenge to environmental impact assessment procedures, [in:] Materials of the International Scientific Conference „Geography and environment: the development of geography in Central and Eastern Europe”, Kaliningrad, Russia, 4-7 June 2001, vol. 1, p. 212.

Roge M., 2001, Oddziaływanie gazociagu tranzytowego Jamał - Europa Zachodnia na środowisko [Environmental impact of the transit gas pipeline Yamal - Western Europe; in Polish], Ogólnopolska Konferencja Naukowa „Gospodarowanie zasobami naturalnymi zgodnie z zasadami zrównoważonego rozwoju”, Mierki, 10-12.10.2001, Polskie Towarzystwo Geofizyczne, Oddział w Warszawie, Warszawa, pp. 70-75.

Studium ochrony przyrody w związku z budowa polskiego odcinka gazociagu Rosja - Europa Zachodnia [A study in the environmental protection in connection with the construction of the Polish segment of the gas pipeline Russia - Western Europe; in Polish], 1996a, [in:] Materials for the Seminar of the PHARE Project No. EC/EPP/92/102. CES Consulting Engineers Salzgitter GmbH (Germany), Eko-Konsult (Poland), Warszawa, November 1996.

Studium ochrony przyrody w zwiazku $z$ budowa polskiego odcinka gazociagu Rosja - Europa Zachodnia [A study in environmental protection in connection with the construction of 
the Polish segment of the gas pipeline Russia - Western Europe; in Polish], 1996b, CES Consulting Engineers Salzgitter GmbH (Germany), Ingenieurbüro Nickel GmbH (Germany), Eko-Konsult (Poland). December 1996.

System gazociagów tranzytowych przez terytorium Rzeczypospolitej Polskiej. Ocena oddziatywania na środowisko [The system of transit gas pipelines crossing the territory of the Republic of Poland. Environmental Impact Assessment; in Polish], 1993, Instytut Inżynierii Ochrony Środowiska, Politechnika Wrocławska, Wrocław. 